\title{
中国成熟林植被和土壤固碳速率对气候变化的响应
}

\author{
黄 玫 ${ }^{*}$ 侯 晶 ${ }^{1,2}$ 唐旭利 ${ }^{3}$ 郝 曼 1,2 \\ ${ }^{1}$ 中国科学院地理科学与资源研究所生态系统网络观测与模拟重点实验室, 北京 $100101 ;{ }^{2}$ 中国科学院大学, 北京 $100049 ;{ }^{3}$ 中国科学院华南植物园, \\ 广州 510650
}

\begin{abstract}
摘 要 基于B2气候变化情景数据, 利用大气-植被相互作用模式AVIM2, 模拟预测了1981-2040年中国成熟林植被和土壤 固碳速率的时空变化特征及其对气候变化的响应。结果表明, 中国森林区域平均气温从1981年的 $7.8{ }^{\circ} \mathrm{C}$ 增加到 2040 年的9.0 ${ }^{\circ} \mathrm{C}$, 森林区域降水量略有增加。成熟林植被碳总量从 8.56 Pg C增加到9.7 Pg C, 植被固碳速率在 $-0.054-0.076 \mathrm{Pg} \mathrm{C} \cdot \mathrm{a}^{-1}$ 之间波动, 平 均值为 $0.022 \mathrm{Pg} \mathrm{C} \cdot \mathrm{a}^{-1}$ 。成熟林土壤碳总量从 $30.2 \mathrm{Pg} C$ 增加到30.72 Pg C, 土壤固碳速率在 $-0.035-0.072 \mathrm{Pg} C \cdot \mathrm{a}^{-1}$ 之间波动, 平均 值为 $0.010 \mathrm{PgC} \cdot \mathrm{a}^{-1}$ 。虽然研究时段内中国植被和土壤固碳总量均没有显著变化趋势, 但区域植被和土壤固碳速率对气候变化 的响应具有显著空间差异。未来在气温增幅较大的东北和东南林区, 特别是在东北的长白山林区, 森林植被和土壤固碳速率 将大大降低; 而在气温增幅不大的西南林区南部和其他林区, 植被和土壤固碳速率将提高。统计结果表明未来气候变暖不利 于成熟林固碳。
\end{abstract}

关键词 中国; 森林; 固碳速率; 气候变化; AVIM2

引用格式: 黄玫, 侯晶, 唐旭利, 郝曼 (2016). 中国成熟林植被和土壤固碳速率对气候变化的响应. 植物生态学报, 40, 416-424. doi: 10.17521/cjpe.2015.0382

\section{Response of vegetation and soil carbon accumulation rate for China's mature forest on cli- mate change}

HUANG $\mathrm{Mei}^{1^{*}}$, HOU Jing ${ }^{1,2}$, TANG Xu-Li ${ }^{3}$, and HAO Man ${ }^{1,2}$

${ }^{1}$ Key Laboratory of Ecosystem Network Observation and Modeling, Institute of Geographic Sciences and Natural sources Research, Chinese Academy of Sciences, Beijing 100101, China; ${ }^{2}$ University of Chinese Academy of Sciences, Beijing 100049, China; and ${ }^{3}$ South China Botanical Garden, Chinese Academy of Sciences, Guangzhou 510650, China

\section{Abstract}

Aims This study aims to evaluate the impacts of future climate change on vegetation and soil carbon accumulation rate in China's forests.

Methods The vegetation and soil carbon storage were predicted by the atmosphere-vegetation interaction model (AVIM2) based on B2 climate change scenario during the period of 1981-2040. This study focused on mature forests in China and the forested area maintained constant over the study period. The carbon accumulation rate in year $\mathrm{t}$ is defined as the carbon storage of year $t$ minus that of year $t-1$.

Important findings Under B2 climate change scenario, mean air temperature in China's forested area was projected to rise from $7.8{ }^{\circ} \mathrm{C}$ in 1981 to $9.0^{\circ} \mathrm{C}$ in 2040 . The total vegetation carbon storage was then estimated to increase from 8.56 Pg C in 1981 to $9.79 \mathrm{Pg} \mathrm{C}$ in 2040, meanwhile total vegetation carbon accumulation rate was estimated to fluctuate between $-0.054-0.076 \mathrm{Pg} \mathrm{C} \cdot \mathrm{a}^{-1}$, with the average of $0.022 \mathrm{Pg} \mathrm{C} \cdot \mathrm{a}^{-1}$. The total soil carbon storage was estimated to increase from 30.2 Pg C in 1981 to $30.72 \mathrm{Pg} \mathrm{C}$ in 2040, and total soil carbon accumulation rate was estimated to vary in the range of $-0.035-0.072 \mathrm{Pg} \mathrm{C} \cdot \mathrm{a}^{-1}$, with the mean of $0.010 \mathrm{Pg} \mathrm{C} \cdot \mathrm{a}^{-1}$. The response of vegetation and soil carbon accumulation rate to climate change had significant spatial difference in China although the two time series did not show significant trend over the study period. Our results also showed warming was not in favor of forest carbon accumulation, so in the northeastern and southeastern forested area, especially in the Changbai Mountain, with highest temperature increase in the future, the vegetation and soil carbon accumulation rate were estimated to decrease greatly. However, in the southern of southwestern forested area and other forested area, with relatively less temperature increase, the vegetation and soil carbon accumulation rate was estimated to increase in the future.

Key words China; forest; carbon accumulation rate; climate change; AVIM2

收稿日期Received: 2015-10-22 接受日期Accepted: 2016-03-25

*E-mail: huangm@igsnrr.ac.cn 
Citation: Huang M, Hou J, Tang XL, Hao M (2016). Response of vegetation and soil carbon accumulation rate for China’s mature forest on climate change. Chinese Journal of Plant Ecology, 40, 416-424. doi: 10.17521/cjpe.2015.0382

森林生态系统是大气的主要碳汇, 其通过固定 大量的大气 $\mathrm{CO}_{2}$ 在缓解气候变暖中发挥重要作用 (Schimel et al., 2001)。过去20年全球平均气温每年 上升 $0.027{ }^{\circ} \mathrm{C}$, 未来100年, 根据不同的情景, 全球 平均气温预计将增加1.8-4.0 ${ }^{\circ} \mathrm{C}$ (IPCC, 2007)。全球 范围的气温和降水量变化将通过影响森林生态系统 的结构和功能而影响森林生态系统的净碳吸收 (Lenihan et al., 2003; Matala et al., 2005)。

中国区域平均气温在过去 100 年已升高 $0.5-0.8$ ${ }^{\circ} \mathrm{C}$, 升温速率高于全球平均升温速率, 区域平均降 水量虽然没有明显变化趋势, 但是降水量的季节分 配和空间分布格局却发生了较大改变(Ding et al., 2006), 这些变化直接影响了森林生态系统碳汇强 度(Piao et al., 2005)。研究表明, 中国森林生态系统 在过去几十年是一个碳汇(Fang et al., 2001), 但是 森林的碳汇强度会随着气候变化而改变(Fang et al., 2003)。森林生态系统碳汇强度对气候变化的响应随 着森林所处的地理环境、生态气候区和森林类型的 变化而不同(Lindner et al., 2010)。因此研究不同区 域森林植被和土壤固碳速率的差别及其对气候变化 的响应具有重要意义。

中国过去开展了大量气候变化对陆地生态系统 碳通量及碳平衡影响的研究, 如 $\mathrm{Ji}$ 等(2008)预测了 未来中国陆地生态系统净初级生产力 $(N P P)$ 、净生 态系统生产力 $(N E P)$ 、植被和土壤碳的变化趋势, Zhao等(2013)预测了未来中国区域植被 $N P P$ 的变 化。有关气候变化对森林生态系统碳汇强度影响的 研究方面, Ju等(2007)预测了中国森林生态系统NPP 和 $N E P$ 等对气候变化的响应, 指出中国森林的 $N E P$ 在2020年达到峰值后下降。Peng等(2009)预测未来 气候变化情景下东北森林 $N P P$ 总量到2030年将增加 $10 \%-12 \%$ 。以上研究主要关注森林 $N P P$ 和 $N E P$ 对气 候变化的响应, $N P P$ 和 $N E P$ 是生态系统通量, 其变 化在一定程度上能反映森林碳汇强度的变化, 但是 不能直接反映森林土壤和植被碳咜量的变化速率。

因此目前还缺乏气候变化对中国森林植被和土壤碳 它量变化速率的影响研究。Xu等(2010)通过生物量 与林龄的关系预测了中国森林2000-2050年生物量 的变化, 但其预测不包含气候变化的影响。
随着全球变暖的加剧, 森林植被和土壤固碳速 率及其变化正成为研究热点。本文在假定中国森林 面积不变且森林都为成熟林的前提下, 从成熟林固 碳的角度研究气候变化对中国森林固碳速率的影 响, 重点关注未来中国区域气温和降水量格局的改 变对森林植被和土壤固碳速率的影响及机理。

\section{1 数据和方法}

\section{1 数据}

模型驱动数据是许吟隆和Jones (2004) 以及许 吟隆等(2005，2006)利用英国Hadley中心发展的区 域气候模式系统(PRECIS)所预测的未来 $\mathrm{B} 2$ 气候变 化情景下中国区域50 km $\times 50 \mathrm{~km}$ 空间分辨率的逐 日气候变化情景数据, 这套数据曾用于气候变化对 中国区域21世纪碳通量影响的预测(Ji et al., 2008)。 土壤质地数据是在分辨率为 $0.1^{\circ} \times 0.1^{\circ}$ 经纬度网格 的中国土壤质地(张时煌等, 2004)分类数据的基础 上, 在Arc-GIS软件平台上进行重采样得到的。森林 植被按照国际地圈生物圈计划(IGBP)的植被功能分 类标准分为: 常绿针叶林、常绿阔叶林、落叶针叶 林、落叶阔叶林、混交林。

\section{2 方法}

\subsection{1 固碳速率的定义}

本研究对固碳速率的定义为:

$$
U_{n}=\frac{C_{n}-C_{n-1}}{\Delta T}
$$

其中 $U_{n}$ 表示第 $n$ 年森林植被或土壤的固碳速率, $C_{n}$ 和 $C_{n-1}$ 分别表示第 $n$ 和 $n-1$ 年森林植被或土壤碳储 量。 $\Delta T$ 为时间差, 在此定义为 1 年。

本研究假定: 1)未来森林面积不发生变化; 2)森 林为成熟林, 未来森林龄级分布、组成结构不发生 变化。

\subsection{2 模型简介}

本研究采用大气-植被相互作用模型(AVIM2) 模拟1981-2040年中国森林生态系统植被和土壤碳 固碳速率变化。AVIM2是基于过程的生态系统碳循 环模型, 包含3个子模块, 分别是物理过程模块、植 物生理生长模块和土壤碳氮循环模块。3个子模块之 间是相互作用和实时动态耦合的。AVIM2能够较好 
地模拟生态系统的水、热、碳通量, 目前已被广泛 应用于各种时空尺度的中国区域碳通量模拟。有关 模型各子模块的详细介绍可参考相关文献(李银鹏 和季劲钧, 2001; 季劲钧等, 2005; 黄玫等, 2006; Lu \& Ji, 2006)。

\subsection{3 统计方法}

文章中采用的统计方法包括线性趋势分析和简 单相关分析。线性趋势分析方法通过线性拟合方程 $(y=a x+b)$ 分析固碳速率的变化趋势, 即:

$a=\left[n \sum_{i=1}^{n} x_{i} y_{i}-\sum_{i=1}^{n} x_{i} \sum_{i=1}^{n} y_{i}\right] /\left[n \sum_{i=1}^{n} x_{i}^{2}-\left(\sum_{i=1}^{n} x_{i}\right)^{2}\right]$

其中, $n$ 代表年数, $x_{i}$ 代表年份 $(1,2,3, \ldots \ldots, n), y_{i}$ 为第 $i$ 年的固碳速率大小。

变量 $x$ 和 $y$ 的简单相关系数 $r$ 的计算公式为:

$$
r=\frac{\sum\left(x_{i}-\bar{x}\right)\left(y_{i}-\bar{y}\right)}{\sqrt{\sum\left(x_{i}-\bar{x}\right)^{2} \sum\left(y_{i}-\bar{y}\right)^{2}}}
$$

其中, $x_{i}$ 和 $y_{i}$ 分别为第 $i$ 年 $x$ 和 $y$ 的值, $\bar{x}$ 和 $\bar{y}$ 则分别为 时间序列 $x$ 和 $y$ 的平均值。

\section{2 结果}

\section{1 模型模拟结果验证}

AVIM2模型曾对站点到区域尺度的陆地生态 系统碳循环进行过模拟, 模拟的植被生物量和土壤 碳库在合理范围内(李银鹏和季劲钧, 2001; 季劲钧 等, 2005; 黄玫等, 2006; Lu \& Ji, 2006; Ji et al., 2008)。由于模型过去对森林生态系统的验证较少, 本研究采用中国科学院战略性先导科技专项项目在 2011-2014年的样地调查数据对模型模拟的2012年 森林生物量和土壤碳储量进行了进一步的验证。

模型研究的空间分辨率为 $50 \mathrm{~km}$, 我们采用 50 $\mathrm{km}$ 网格里所有森林调查样地的平均值与模拟结果 进行比较。模型假设森林为成熟林, 理论上应该挑 选林龄为 100 年以上的森林样地数据进行验证, 但 由于能用于比较的老龄林的样地调查数据较少, 因 此在本研究中挑选了林龄大于 80 年的数据用于比 较。计算下来, 共有 63 个模型网格数据中包含林龄 超过 80 年的森林样地观测数据, 因此对每个模型网 格中包含的森林样地调查数据进行了平均, 然后与 模型网格数据进行对比。
经统计, 验证样地的平均林龄为 91 年。观测样 地平均植被碳为 $8.04 \mathrm{~kg} \mathrm{C} \cdot \mathrm{m}^{-2}$, 标准偏差是 $2.22 \mathrm{~kg}$ $\mathrm{C} \cdot \mathrm{m}^{-2}$ 。模拟的平均植被碳为 $9.28 \mathrm{~kg} \mathrm{C} \cdot \mathrm{m}^{-2}$, 标准偏 差是 $1.9 \mathrm{~kg} \mathrm{C} \cdot \mathrm{m}^{-2}$ 。观测的样地平均土壤碳为 $13.7 \mathrm{~kg}$ $\mathrm{C} \cdot \mathrm{m}^{-2}$, 标准偏差为 $7.3 \mathrm{~kg} \mathrm{C} \cdot \mathrm{m}^{-2}$; 而模拟的平均土壤 碳为 $16.1 \mathrm{~kg} \mathrm{C} \cdot \mathrm{m}^{-2}$, 标准偏差为 $7.6 \mathrm{~kg} \mathrm{C} \cdot \mathrm{m}^{-2}$ 。散点图 上模拟的植被和土壤碳密度与观测数据之间的相关 系数平方分别达到 0.27 和 $0.20, p$ 值均小于 0.001 (图 1)。比较来看, 对植被碳的模拟效果优于对土壤碳 的模拟, 模拟的土壤碳密度的均方根误差(6.95)大 于模拟的植被碳密度的误差(1.78)。

进一步比较了观测与模拟的不同类型森林植被 和土壤碳密度的差异(表1), 模拟的不同类型森林植 被碳密度均高于观测的平均值, 偏差在7.6\%-25.9\% 之间。偏差最大的植被类型如落叶针叶林, 其平均 林龄较小, 为 85 年。可能是由于林龄的原因造成了 模拟的较大偏差。观测的不同植被类型的平均土壤 碳密度在11.3-16.5 $\mathrm{kg} \mathrm{C} \cdot \mathrm{m}^{-2}$ 之间变化, 模拟值则在 11.3-20.7 kg C $\cdot \mathrm{m}^{-2}$ 之间变化。由于模拟的植被碳密 度偏高, 导致模拟的土壤碳密度也相对偏高。除落 叶阔叶林以外, 其余森林类型的相对偏差在 6.7\%$37.0 \%$ 之间。落叶阔叶林由于其平均林龄较高, 为 102年, 模拟的平均植被碳密度与观测值比较接近, 因此土壤碳密度的相对偏差属于合理范围。总之, 从森林类型平均来看, 模拟的植被和土壤碳密度是 相对合理的。

为进一步探究模型基于成熟林假设估计的土壤 和植被碳密度与中国实际森林土壤和植被碳密度的 偏差, 我们不分林龄将所有观测样点的植被和土壤 碳密度与模拟结果进行了比较。结果表明, 观测的 植被碳密度明显比成熟林低, 按植被类型平均在 5.70-6.34 $\mathrm{kg} \mathrm{C} \cdot \mathrm{m}^{-2}$ 之间变化, 而模拟值则在6.65$13.50 \mathrm{~kg} \mathrm{C} \cdot \mathrm{m}^{-2}$ 之间变化。观测的土壤碳密度与成熟 林相比变化不大, 在11.6-17.4 kg C·m ${ }^{-2}$ 之间, 而模 拟的土壤碳密度则在11.9-21.4 $\mathrm{kg} \mathrm{C} \cdot \mathrm{m}^{-2}$ 之间变化。 模拟的植被和土壤碳密度按植被类型的平均值均高 于相应观测值的平均值。具体来看, 偏差最大的是 落叶针叶林, 其观测样地的平均林龄为 29 年, 观测 与模拟的植被和土壤碳密度偏差分别为 $156 \%$ 和 $29 \%$ 。其次是常绿阔叶林, 其平均林龄为 41 年, 平均 偏差分别为 $82 \%$ 和 $38 \%$ 。常绿针叶林的平均林龄为 37年, 模拟的植被和土壤碳密度与观测的偏差分别 

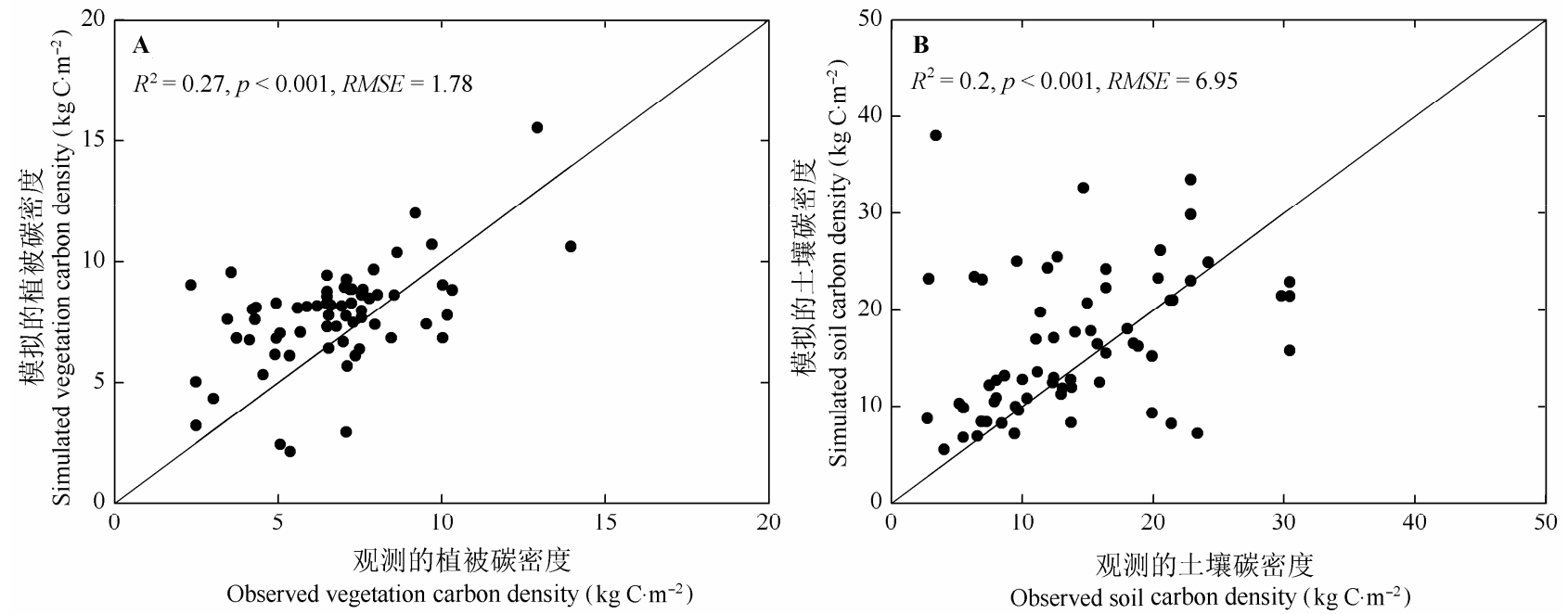

图 1 碳密度观测值与模拟值的比较。 $\mathbf{A}$, 植被。 $\mathbf{B}$, 土壤。 $R M S E$, 均方根误差。

Fig. 1 Comparison of the simulated and observed carbon density. A, Vegetation. B, Soil. RMSE, root mean square error.

表1 森林类型平均观测与模拟的植被和土壤碳密度比较

Table 1 Comparison of the simulated and observed mean vegetation and soil carbon density among various forest types

\begin{tabular}{|c|c|c|c|c|c|c|c|c|}
\hline \multirow[t]{2}{*}{$\begin{array}{l}\text { 植被类型 } \\
\text { Vegetation type }\end{array}$} & \multirow[t]{2}{*}{$\begin{array}{l}\text { 网格点数 } \\
\text { No. of sites }\end{array}$} & \multirow{2}{*}{$\begin{array}{c}\text { 平均林龄 } \\
\text { Mean stand } \\
\text { age (a) }\end{array}$} & \multicolumn{3}{|c|}{$\begin{array}{c}\text { 植被碳 } \\
\text { Vegetation carbon }\left(\mathrm{kg} \mathrm{C} \cdot \mathrm{m}^{-2}\right)\end{array}$} & \multicolumn{3}{|c|}{$\begin{array}{c}\text { 土壤碳 } \\
\text { Soil carbon }\left(\mathrm{kg} \mathrm{C} \cdot \mathrm{m}^{-2}\right)\end{array}$} \\
\hline & & & $\begin{array}{c}\text { 观测 } \\
\text { Observed }\end{array}$ & $\begin{array}{c}\text { 模拟 } \\
\text { Simulated }\end{array}$ & $\begin{array}{c}\text { 相对偏差 } \\
\text { Relative } \\
\text { deviation (\%) }\end{array}$ & $\begin{array}{c}\text { 观测 } \\
\text { Observed }\end{array}$ & $\begin{array}{c}\text { 模拟 } \\
\text { Simulated }\end{array}$ & $\begin{array}{c}\text { 相对偏差 } \\
\text { Relative } \\
\text { deviation (\%) }\end{array}$ \\
\hline 常绿针叶林 Evergreen coniferous forest & 4 & 82 & 7.8 & 8.4 & 7.7 & 13.4 & 14.3 & 6.7 \\
\hline 常绿阔叶林 Evergreen broad-leaved forest & 4 & 100 & 8.6 & 9.8 & 13.2 & 11.3 & 15.5 & 37.0 \\
\hline 落叶针叶林 Deciduous coniferous forest & 3 & 85 & 10.8 & 13.6 & 25.9 & 15.3 & 18.7 & 22.0 \\
\hline 落叶阔叶林 Deciduous broad-leaved forest & 22 & 102 & 6.3 & 6.8 & 7.6 & 12.0 & 11.3 & -5.8 \\
\hline 混交林 Mixed forest & 30 & 85 & 6.7 & 7.7 & 15.4 & 16.5 & 20.7 & 25.5 \\
\hline
\end{tabular}

为 $24 \%$ 和 $11 \%$; 混交林的平均林龄为 27 年，平均偏 差分别为 $21 \%$ 和 $28 \%$ 。落叶阔叶林的平均林龄为 29 年, 其模拟的植被和土壤碳密度与观测的平均偏差 较小, 分别为 $10 \%$ 和 $5 \%$ 。

总的看来, 模拟的植被和土壤碳密度与成熟林 样点观测值比较的平均偏差分别在 $7.6 \%-25.9 \%$ 和 $-5.8 \%-37.0 \%$ 之间，而与平均林龄在 $29-41$ 年的所有 样点的观测值相比较, 植被和土壤碳密度的偏差则 达到10\%-156\%和5\%-38\%。因此成熟林假设主要使 得模型高估了森林的植被碳密度, 而对森林土壤碳 密度的估计影响相对较小。

\section{2 中国成熟林植被和土壤固碳速率变化趋势}

在B2气候变化情景下, 中国森林区域平均气温 从1981年的7.8 ${ }^{\circ} \mathrm{C}$ 增加到2040年的 $9.0{ }^{\circ} \mathrm{C}$, 呈显著增 加趋势, 增加速率为 $0.032{ }^{\circ} \mathrm{C} \cdot \mathrm{a}^{-1}($ 图 $2 \mathrm{~A})$ 。中国森林 区域降水量略有增加, 增加速率为 $0.7 \mathrm{~mm} \cdot \mathrm{a}^{-1}$ (图 2B)。在以上气候变化情景下, 中国森林成熟林植被 碳总量在1981-2040年期间将从8.56 Pg C增加到9.7
Pg C, 土壤碳总量从1981年的30.20 Pg C增加到 2040年的30.72 Pg C (图2C、2D)。

模型估计的中国森林1981-2010年平均成熟林 植被碳储量为 $8.82 \mathrm{Pg} \mathrm{C}$ 。过去基于森林清查数据估 计的1981-2010年间中国森林植被碳总量在3.8-6.9 Pg C间变化(周玉荣等, 2000; Fang et al., 2001, 2007; Pan et al., 2004; 赵敏和周广胜, 2004; Piao et al., 2005; 徐新良等, 2007; 李怒云等, 2010; Xu et al., 2010; Liu et al., 2012)。由于本研究假设森林为成熟 林, 模拟的森林碳储量总量较其他研究高, 但总的 来说模型估计的植被碳总量是基本合理的。模型估 算的中国成熟森林土壤碳储量在1981-2010年的平 均总量为30.18 Pg C。周玉荣等(2000)估计的中国森 林土壤碳总量为21.02 Pg C。Xie等(2007)估计的为 $34.23 \mathrm{Pg}$ C。由于Xie等(2007)采用的土壤样本较多, 可信度较大，因此模型估计的中国土壤碳储量基本 合理。

1981-2040年间，中国成熟森林的植被固碳速 

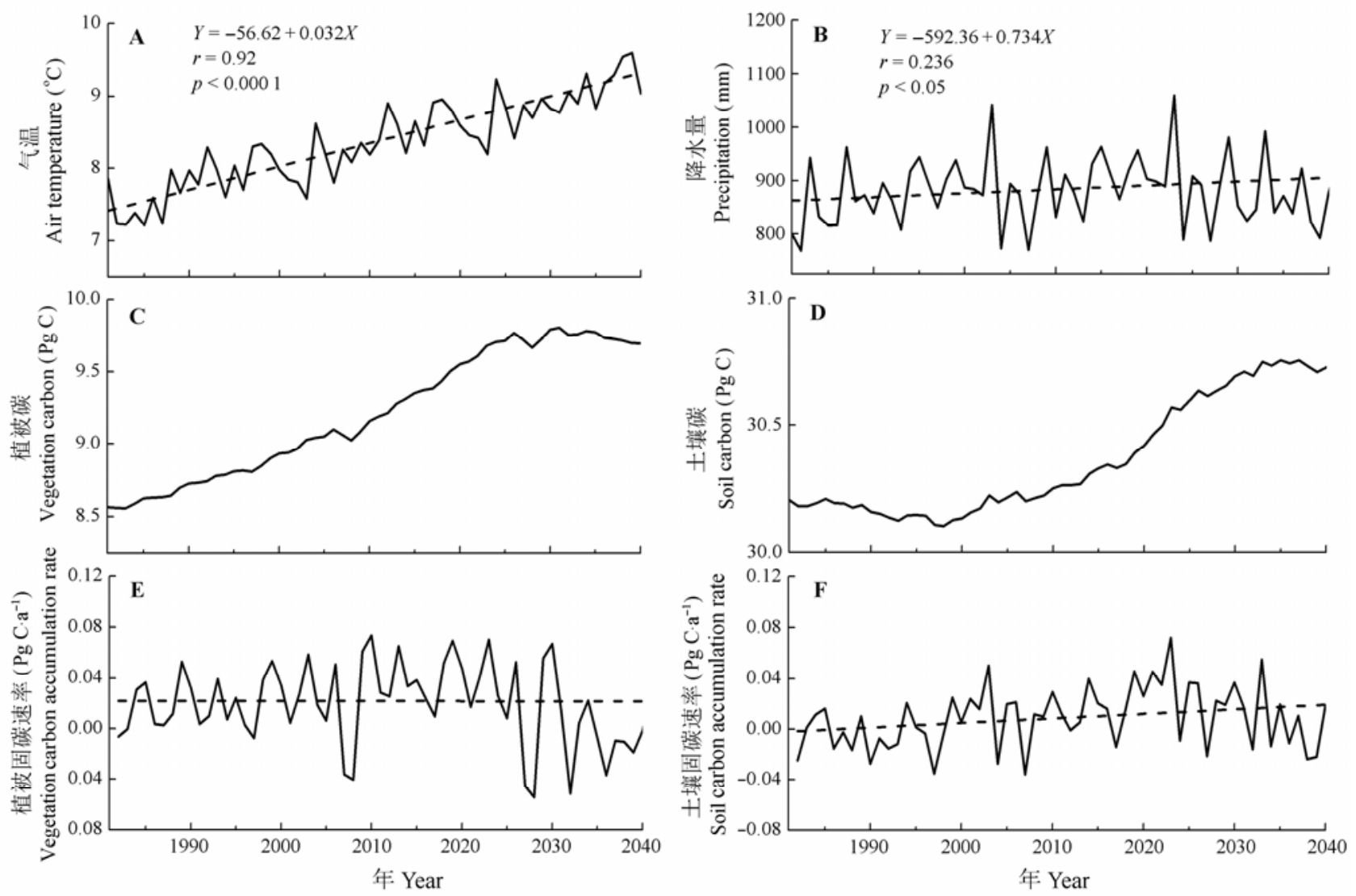

图2 1981-2040年中国成熟林气温、降水量、碳总量和固碳速率变化。A, 年平均气温。 $\mathbf{B}$, 年降水量。C, 植被碳总量。 D, 土 壤碳总量。E, 植被固碳速率。F, 土壤固碳速率。

Fig. 2 The variations of air temperature, precipitation, total carbon amount and carbon accumulation for China's mature forests from 1981-2040. A, Annual mean air temperature. B, Annual precipitation. C, Total vegetation carbon stock. D, Total soil carbon stock. E, Vegetation carbon accumulation rate. F, Soil carbon accumulation rate.

率在-0.054-0.076 Pg C $\cdot \mathrm{a}^{-1}$ 之间波动, 平均值为 $0.022 \mathrm{Pg} \mathrm{C} \cdot \mathrm{a}^{-1}$, 研究时段没有明显变化趋势(图2E)。 中国成熟森林的土壤固碳速率在-0.035-0.072 Pg $\mathrm{C} \cdot \mathrm{a}^{-1}$ 之间波动, 平均值为 $0.010 \mathrm{Pg} \mathrm{C} \cdot \mathrm{a}^{-1}$, 也没有明 显变化趋势(图2F)。

模型模拟的中国森林植被固碳速率比其他人的 研究结果都偏小, 比如Fang等(2007)估计的平均植 被固碳速率为 $0.075 \mathrm{Pg} \mathrm{C} \cdot \mathrm{a}^{-1}$, Piao等(2009)估计的20 世纪 80 年代中国森林植被固碳速率为 $(0.058 \pm$ 0.026) Pg C $\cdot a^{-1}, 20$ 世纪 90 年代为 $(0.092 \pm 0.044) P g$ $\mathrm{C} \cdot \mathrm{a}^{-1}$ 。本研究估计的土壤固碳速率在Fang等(2007) 估计的0.04-0.07 Pg C $\cdot \mathrm{a}^{-1}$ 的范围内。如果定义植被 和土壤固碳速率之和为森林总固碳速率的话, 那么 1981-2010年中国森林植被固碳速率和土壤总固碳 速率的平均值分别为 $0.0301 \mathrm{Pg} \mathrm{C} \cdot \mathrm{a}^{-1}$ 和 $0.0510 \mathrm{Pg}$ $\mathrm{C} \cdot \mathrm{a}^{-1}$ 。由于对森林植被固碳速率的低估, 估计的森 林总固碳速率为 $0.0811 \mathrm{Pg} \mathrm{C} \cdot \mathrm{a}^{-1}$, 比Pan等(2011)估 计的1990-1999年的0.14 Pg C $\cdot \mathrm{a}^{-1}$ 和2000-2007年的
$0.18 \mathrm{PgC} \cdot \mathrm{a}^{-1}$ 小。考虑到本研究的成熟林假设, 估算 的总固碳速率偏小也是合理的。

\section{3 中国成熟林植被和土壤固碳速率的空间分布}

1981-2010年中国成熟林植被固碳速率和土壤 固碳速率平均值的空间分布如图3所示。由图3可见, 成熟林的植被固碳速率以东北林区为最高, 植被固 碳速率最高可达100 g C $\cdot \mathrm{m}^{-2} \cdot \mathrm{a}^{-1}$, 一般都在 $20 \mathrm{~g}$ $\mathrm{C} \cdot \mathrm{m}^{-2} \cdot \mathrm{a}^{-1}$ 以上。东南林区植被固碳速率在 $20-40 \mathrm{~g}$ $\mathrm{C} \cdot \mathrm{m}^{-2} \cdot \mathrm{a}^{-1}$ 之间, 西南林区部分森林植被固碳速率能 达到20 g C $\cdot \mathrm{m}^{-2} \cdot \mathrm{a}^{-1}$ 以上, 其余林区森林植被固碳速 率都在 $20 \mathrm{~g} \mathrm{C} \cdot \mathrm{m}^{-2} \cdot \mathrm{a}^{-1}$ 以内(图3A)。

中国成熟林土壤固碳速率的空间分布格局与植 被固碳速率格局基本相似。土壤固碳速率以东北林 区为最高, 东北大兴安岭北部森林土壤固碳速率在 20-40 g C $\cdot \mathrm{m}^{-2} \cdot \mathrm{a}^{-1}$ 之间, 其余森林土壤的固碳速率都 在 $40 \mathrm{~g} \mathrm{C} \cdot \mathrm{m}^{-2} \cdot \mathrm{a}^{-1}$, 最高可达 $120 \mathrm{~g} \mathrm{C} \cdot \mathrm{m}^{-2} \cdot \mathrm{a}^{-1}$ 。东南林 区和西南林区大部分森林土壤固碳速率在20-40 g $\mathrm{C} \cdot \mathrm{m}^{-2} \cdot \mathrm{a}^{-1}$ 之间, 其余林区的固碳速率都在 $20 \mathrm{~g}$ 
$\mathrm{C} \cdot \mathrm{m}^{-2} \cdot \mathrm{a}^{-1}$ 以下(图3B)。

\section{4 成熟林植被和土壤固碳速率的未来变化趋势}

从全国总量上来看, 研究时段内植被和土壤的 固碳速率没有明显变化趋势。我们计算了2011-2040 年平均的植被和土壤固碳速率与1981-2010年相应 平均值之差的空间分布, 从区域变化的角度来看植 被和土壤固碳速率的未来变化趋势。图4A显示, 未 来中国东北长白山的植被固碳速率减少最多, 最大 减少量为 $65 \mathrm{~g} \mathrm{C} \cdot \mathrm{m}^{-2} \cdot \mathrm{a}^{-1}$; 小兴安岭和大兴安岭南段 大部分森林植被减少量在 $20 \mathrm{~g} \mathrm{C} \cdot \mathrm{m}^{-2} \cdot \mathrm{a}^{-1}$ 以内; 东南 林区森林植被固碳速率均减少, 部分森林减少量达 $40 \mathrm{~g} \mathrm{C} \cdot \mathrm{m}^{-2} \cdot \mathrm{a}^{-1}$; 西南林区的西藏和云南南部林区的 植被固碳速率将增加, 大部分林区增加量在 $20 \mathrm{~g} \mathrm{C}$. $\mathrm{m}^{-2} \cdot \mathrm{a}^{-1}$ 以内, 部分林区增加量达到 $40 \mathrm{~g} \mathrm{C} \cdot \mathrm{m}^{-2} \cdot \mathrm{a}^{-1}$ 。秦 岭及其以北太行山一带林区的植被固碳速率增加量 在 $20 \mathrm{~g} \mathrm{C} \cdot \mathrm{m}^{-2} \cdot \mathrm{a}^{-1}$ 以内, 部分林区达到 $40 \mathrm{~g} \mathrm{C} \cdot \mathrm{m}^{-2} \cdot \mathrm{a}^{-1}$ 。
与1981-2010年平均土壤固碳速率相比, 未来 东北长白山的土壤固碳速率减少最多, 最大减少量 可达65 $\mathrm{g} \mathrm{C} \cdot \mathrm{m}^{-2} \cdot \mathrm{a}^{-1}$, 小兴安岭和大兴安岭南段森林 土壤固碳速率减少量在 $20 \mathrm{~g} \mathrm{C} \cdot \mathrm{m}^{-2} \cdot \mathrm{a}^{-1}$ 以内, 东南林 区森林土壤固碳速率均减少, 大部分减少量在 20-40 g C $\cdot \mathrm{m}^{-2} \cdot \mathrm{a}^{-1}$ 之间。西南林区除西藏东部和云南 南部部分森林的土壤固碳速率将增加外, 大部分森 林土壤固碳速率减少量在 $20 \mathrm{~g} \mathrm{C} \cdot \mathrm{m}^{-2} \cdot \mathrm{a}^{-1}$ 以内, 部分 减少量达 $40 \mathrm{~g} \mathrm{C} \cdot \mathrm{m}^{-2} \cdot \mathrm{a}^{-1}$ 。秦岭以北太行山一带林区的 土壤固碳速率增加量在 $20 \mathrm{~g} \mathrm{C} \cdot \mathrm{m}^{-2} \cdot \mathrm{a}^{-1}$ 以内, 部分林 区达到 $40 \mathrm{~g} \mathrm{C} \cdot \mathrm{m}^{-2} \cdot \mathrm{a}^{-1}$ 。秦岭部分林区土壤固碳速率 将减少, 减少量在 $20 \mathrm{~g} \mathrm{C} \cdot \mathrm{m}^{-2} \cdot \mathrm{a}^{-1}$ 以内(图4B)。

\section{3 讨论}

本研究定义某年的植被或土壤固碳速率为当年 的植被或土壤碳库与上一年植被或土壤碳库之差,
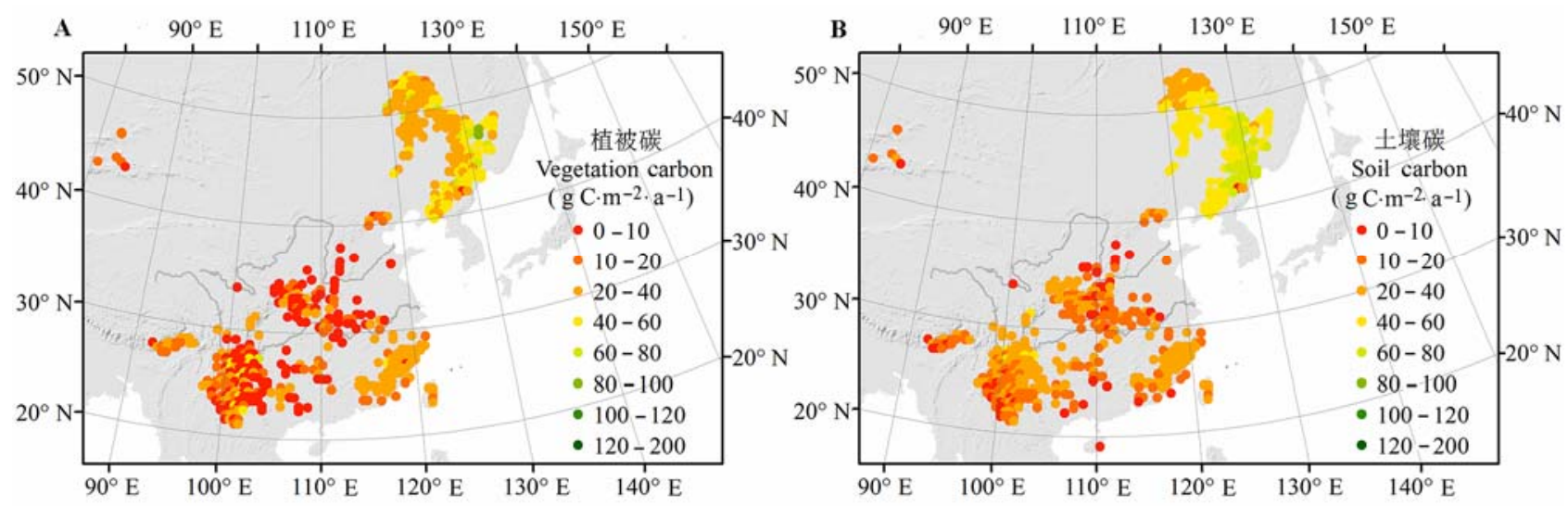

图3 1981-2010年平均成熟林固碳速率的空间分布。A，植被固碳速率。 B，土壤固碳速率。

Fig. 3 The spatial distribution of forest carbon accumulation rate averaged over 1981-2010. A, Vegetation carbon accumulation rate. B, Soil carbon accumulation rate.
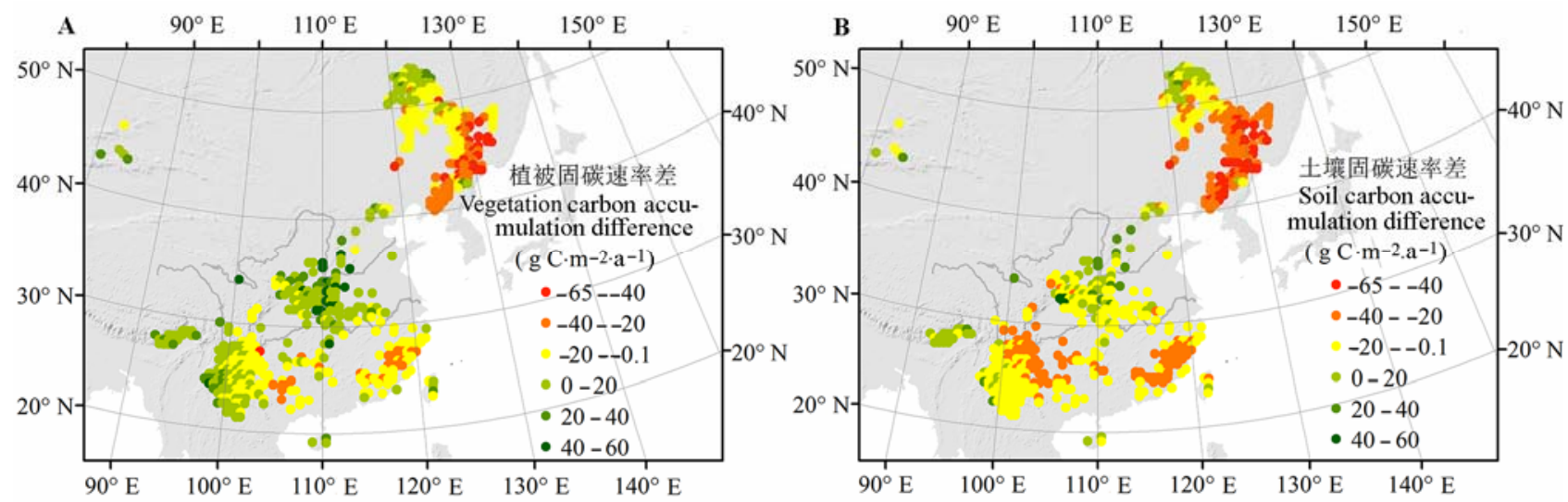

图4 2011-2040年与1981-2010年平均固碳速率之差。A, 植被固碳速率差。 B, 土壤固碳速率差。

Fig. 4 The difference of average carbon accumulation rate between 2011-2040 and 1981-2010. A, Difference of vegetation carbon accumulation rate. B, Difference of soil carbon accumulation rate. 
由此定义某年的气温差或降水量差为当年的年平均 气温或年降水量与上一年的年平均气温或年降水量 之差。我们统计了1981-2040年间植被平均固碳速率 和土壤平均固碳速率与平均气温差和平均降水量差 的关系, 发现植被和土壤固碳速率与降水量差没有 明显的相关关系, 但是跟气温差有明显的负相关关 系(图5)。森林植被和土壤的固碳速率与降水量差没 有明显相关关系是可以理解的, 因为对大多数森林 生态系统来说, 降水量并不是其限制因子, 因此年 际的降水量变化对其固碳速率影响不大。气温升高 对森林生态系统的作用是多方面的, 一方面气温升
高可以增加叶片的光合作用而有利于森林固碳，另 一方面气温升高增加了树木的呼吸和土壤呼吸, 从 而不利于植被和土壤固碳。从模拟结果来看, 气候 变暖并不利于中国成熟林植被和土壤固碳速率的增 加。相比之下, 土壤固碳速率与年际气温差的负相 关 $\left(R^{2}=0.314, p<0.001\right)$ 比植被固碳速率与年际气 温差的负相关 $\left(R^{2}=0.126, p<0.001\right)$ 更明显，气候变 暖对土壤固碳速率的影响更显著。

通过2011-2040年平均气温与1981-2010年平均 气温差的空间分布图(图6), 可以理解未来成熟林固 碳速率变化的原因。B2气候变化情景下，东北林区
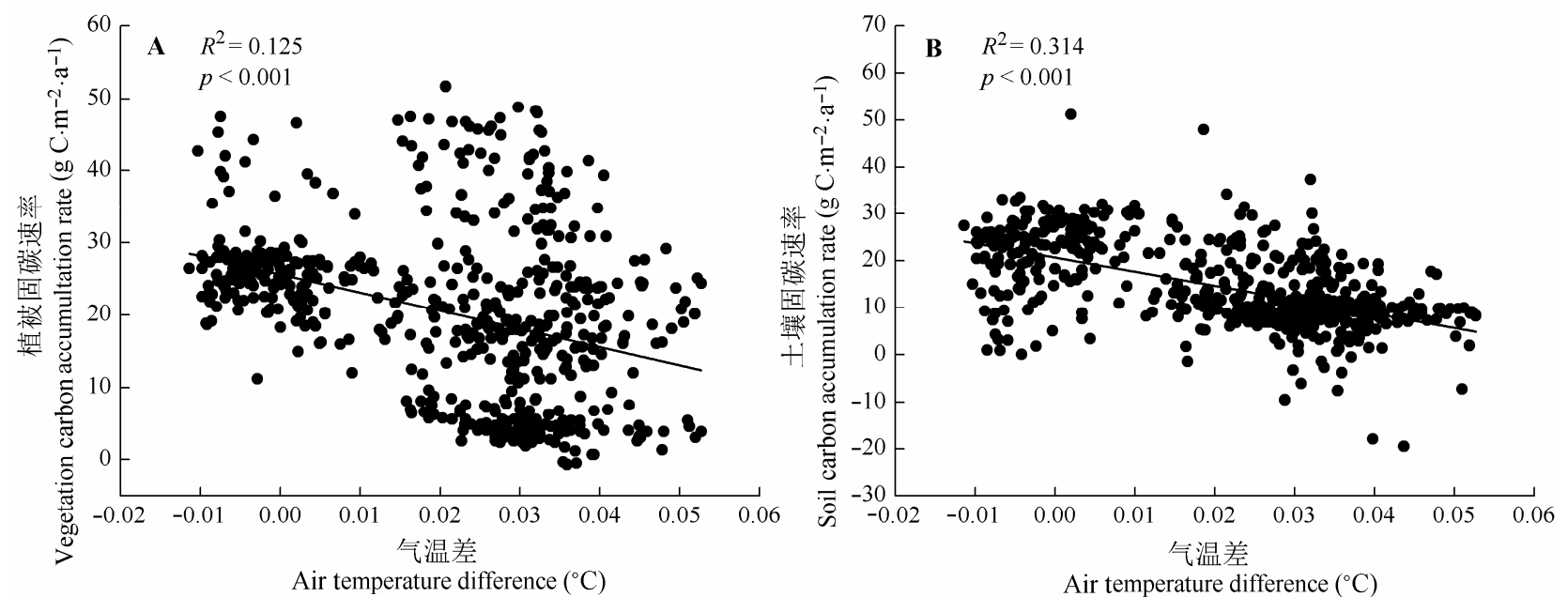

图5 固碳速率对年平均气温差的敏感性。A, 植被固碳速率。 $\mathbf{B}$, 土壤固碳速率。

Fig. 5 The sensitivity of carbon accumulation rate to mean annual air temperature difference. A, Vegetation carbon accumulation rate. $\mathbf{B}$, Soil carbon accumulation rate.

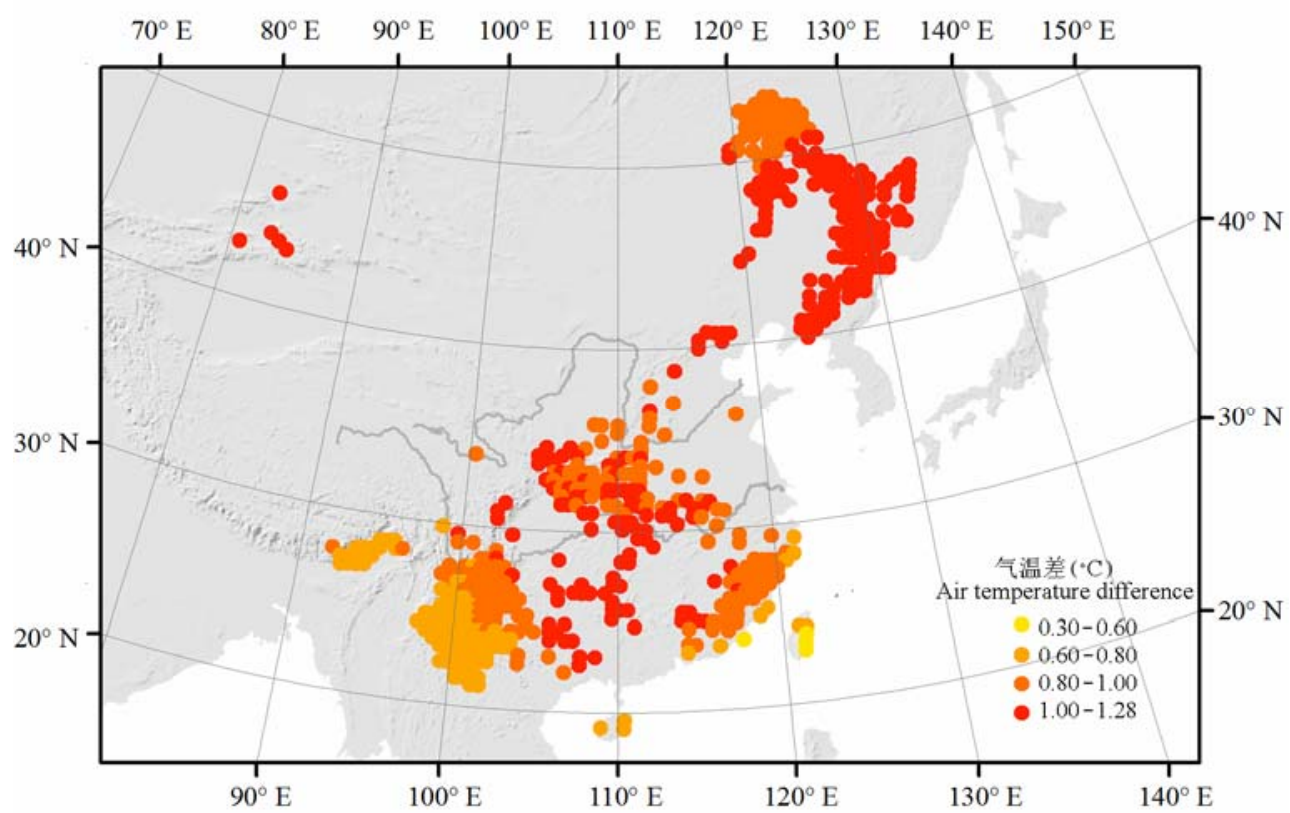

图6 森林区域2011-2040年平均气温与1981-2010年平均气温之差的空间分布。

Fig. 6 The spatial distribution of air temperature difference between 2011-2040 and 1981-2010 across forested area.

www.plant-ecology.com 
2011-2040年的平均气温与1981-2010年平均气温差 都在 $1{ }^{\circ} \mathrm{C}$ 以上, 最高达 $1.28{ }^{\circ} \mathrm{C}$ 。小兴安岭和大兴安 岭南段增温也在 $1{ }^{\circ} \mathrm{C}$ 以上。对比图4可发现东北大部 分升温幅度大的林区, 植被和土壤固碳速率减少最 多。东南林区的增温在0.6-0.8 ${ }^{\circ} \mathrm{C}$ 之间, 而该林区的 土壤和植被固碳速率降低也较多。未来西南林区的 气温增加最少, 青藏高原南麓和云南的大部分区域 的增温在0.6-0.8 ${ }^{\circ} \mathrm{C}$ 之间, 对比图4可看出这些区域 的植被固碳速率将提高, 而土壤固碳速率降低得不 多。秦岭以北太行山一带林区虽然增温幅度也较高, 在0.8-1.0 ${ }^{\circ} \mathrm{C}$ 之间, 但是其植被和土壤固碳速率都增 加, 说明除气温变化以外, 其他气象因子对固碳速 率的变化也有一定的影响。

\section{4 结论}

本研究利用 AVIM2 模型模拟与预测了 19812040年中国成熟林土壤和植被固碳速率的时空变化 特征, 并分析了土壤和植被固碳速率变化的原因, 得出以下结论:

在不考虑新造林及气候变化的 B2 情景下, 1981-2040年, 中国成熟森林的植被固碳速率在 -0.054-0.076 Pg C $\cdot \mathrm{a}^{-1}$ 之间波动, 平均值为 $0.022 \mathrm{Pg}$ $\mathrm{C} \cdot \mathrm{a}^{-1}$; 土壤固碳速率在 $-0.035-0.072 \mathrm{Pg} \mathrm{C} \cdot \mathrm{a}^{-1}$ 之间变 化, 平均值为 $0.010 \mathrm{Pg} \mathrm{C} \cdot \mathrm{a}^{-1}$, 研究时段内植被固碳 速率和土壤固碳速率均没有明显变化趋势。

虽然全国森林每年的固碳总量没有明显变化趋 势, 但未来森林固碳速率变化区域差异明显。研究 时段内后30年与前30年相比, 未来东北和东南林区 森林植被固碳速率减少, 而西南林区的南部和其他 林区的植被固碳速率将增加; 全国森林土壤固碳速 率除藏南、华中和东北北部的部分森林以外, 其余 大部分森林的土壤固碳速率均减少, 其中东北长白 山森林土壤固碳速率减少最多。

未来中国森林植被和土壤固碳变化主要由气温 和降水量未来变化的空间差异引起, 总的来看, 气 温增加不利于森林植被和土壤固碳。

虽然模型研究得到的以上结论只是针对成熟林 的, 与现实中国森林的情况并不符合, 但是模拟结 果可以帮助我们了解气候变化对不同林区森林固碳 速率的影响, 以利于决策者采取应对措施。

基金项目 中国科学院战略性先导科技专项(XDA05050209)和国家自然科学基金(41271118)。

\section{参考文献}

Ding YH, Ren GY, Shi GY, Gong P, Zheng XH, Zhai PM, Zhang DE, Zhao ZC, Wang SW, Wang HJ, Luo Y, Chen DL, Gao XJ, Dai XS (2006). National assessment report of climate change (I): Climate change in China and its future trend. Advances in Climate Change Research, 2(1), 3-8.

Fang JY, Chen AP, Peng CH, Zhao SQ, Ci LJ (2001). Changes in forest biomass carbon storage in China between 1949 and 1998. Science, 292, 2320-2322.

Fang JY, Guo ZD, Piao SL, Chen AP (2007). Terrestrial vegetation carbon sinks in China, 1981-2000. Science in China Series D: Earth Sciences, 50, 1341-1350.

Fang JY, Piao SL, Field CB, Pan YD, Guo QH, Zhou LM, Peng $\mathrm{CH}$, Tao S (2003). Increasing net primary production in China from1982 to 1999. Frontiers in Ecology and the Environment, 1, 293-297.

Huang M, Ji JJ, Cao MK, Li KR (2006). Modeling study of vegetation shoot and root biomass in China. Acta Ecologica Sinica, 26, 4156-4163. (in Chinese with English abstract) [黄玫, 季劲钧, 曹明奎, 李克让 (2006). 中国区域植被 地上与地下生物量模拟. 生态学报, 26, 4156-4163.]

IPCC (Intergovernmental Panel on Climate Change) (2007). Contribution of working group 1 to the fourth assessment report of the intergovernmental panel on climate change. In: Solomon S, Qin D, Manning M, Chen Z, Marquis M, Averyt KB, Tignor M, Miller HL eds. Climate Change in 2007: The Physical Science Basis. Cambridge University Press, Cambridge, UK.

Ji JJ, Huang M, Li KR (2008). Prediction of carbon exchanges between China terrestrial ecosystem and atmosphere in 21st century. Science in China Series D: Earth Sciences, 51, 885-898.

Ji JJ, Huang M, Liu Q (2005). Modeling studies of response mechanism of steppe productivity to climate change in middle latitude semiarid regions in China. Acta Meteorologica Sinica, 63, 257-266. (in Chinese with English abstract) [季劲钧, 黄玫, 刘青 (2005). 气候变化对我国 中纬度半干旱草原生产力影响机理的模拟研究. 气象 学报, 63, 257-266.]

Ju WM, Chen JM, Harvey D, Wang S (2007). Future carbon balance of China's forests under climate change and increasing $\mathrm{CO}_{2}$. Journal of Environmental Management, 85, 538-562.

Lenihan JM, Drapek R, Bachelet D, Neilson RP (2003). Climate change effects on vegetation distribution, carbon, and fire in California. Ecological Applications, 13, 1667-1681.

Li NY, Yang YZ, Chen XT (2010). Develop carbon sequestration forestry for combating climate change: The practice and management of carbon sequestration forestry in China. Science of Soil and Water Conservation, 8, 13-16. (in Chinese with English abstract) [李怒云, 杨炎朝, 陈叙图 (2010). 发展碳汇林业应对气候变化一一国碳汇林业 的实践与管理. 中国水土保持科学, 8, 13-16.]

Li YP, Ji JJ (2001). Simulations of carbon exchange between 
global terrestrial ecosystem and the atmosphere. Acta Geographica Sinica, 56, 379-389. (in Chinese with English abstract) [李银鹏, 季劲钧 (2001). 全球陆地生态系统与 大气之间碳交换的模拟研究. 地理学报, 56, 379-389.]

Lindner M, Maroschek M, Netherer S, Kremer A, Barbati A, Garcia-Gonzalo J, Seidl R, Delzon S, Corona P, Kolström M, Lexer MJ, Marchetti M (2010). Climate change impacts, adaptive capacity, and vulnerability of European forest ecosystems. Forest Ecology Management, 259, 698-709.

Liu SN, Zhou T, Wei LY, Shu Y (2012). The spatial distribution of forest carbon sinks and sources in China. Chinese Science Bulletin, 57, 1699-1707.

Lu JH, Ji JJ (2006). A simulation and mechanism analysis of long-term variations at land surface over arid/semi-arid area in north China. Journal of Geophysical Research, 111, D09306, doi: 10.1029/2005JD006252.

Matala J, Ojansuu R, Peltola H, Sievänen R, Kellomäki S (2005). Introducing effects of temperature and $\mathrm{CO}_{2}$ elevation on tree growth into a statistical growth and yield model. Ecological Modelling, 181, 173-190.

Pan YD, Birdsey RA, Fang JY, Houghton R, Kauppi PE, Kurz WA, Phillips OL, Shvidenko A, Lewis SL, Canadell JG, Ciais P, Jackson RB, Pacala SW, McGuire AD, Piao SL, Rautiainen A, Sitch S, Hayes D (2011). A large and persistent carbon sink in the world's forests. Science, 333, 988-993.

Pan YD, Luo TX, Birdsey R, Hom J, Melillo J (2004). New estimates of carbon storage and sequestration in China's forests: Effects of age-class and method on inventorybased carbon estimation. Climatic Chang, 67, 211-236.

Peng CH, Zhou XL, Zhao SQ, Wang XP, Zhu B, Piao SL, Fang JY (2009). Quantifying the response of forest carbon balance to future climate change in Northeastern China: Model validation and prediction. Global and Planetary Change, 66, 179-194.

Piao SL, Fang JY, Ciais P, Peylin P, Huang Y, Sitch S, Wang T (2009). The Carbon balance of terrestrial ecosystems in China. Nature, 458, 1009-1013.

Piao SL, Fang JY, Zhu B, Tan K (2005). Forest biomass carbon stocks in China over the past 2 decades: Estimation based on integrated inventory and satellite data. Journal of Geophysical Research, 110, G01006, doi: 10.1029/2005 JG000014.

Schimel DS, House JI, Hibbard KA, Bousquet P, Ciais P, Peylin P, Braswell BH, Apps MJ, Baker D, Bondeau A, Canadell J, Churkina G, Cramer W, Denning AS, Field CB, Friedlingstein P, Goodale C, Heimann M, Houghton RA, Melillo JM, Moore III B, Murdiyarso D, Noble I, Pacala SW, Prentice IC, Raupach MR, Rayner PJ, Scholes RJ, Steffen WL, Wirth C (2001). Recent patterns and mechanisms of carbon exchange by terrestrial ecosystems. $\mathrm{Na}$ ture, 414, 169-172.

Xie ZB, Zhu JG, Liu G, Cadisch G, Hasegawa T, Chen CM, Sun HF, Tang HY, Zeng Q (2007). Soil organic carbon stocks in China and changes from 1980s to 2000s. Global Change Biology, 13, 1989-2007.
Xu B, Guo ZD, Piao SL, Fang JY (2010). Biomass carbon stocks in China's forests between 2000 and 2050: A prediction based on forest biomass-age relationships. Science China Life Sciences, 53, 776-783.

Xu XL, Cao MK, Li KR (2007). Temporal-spatial dynamics of carbon storage of forest vegetation in China. Progress in Geography, 26(6), 1-10. (in Chinese with English abstract) [徐新良, 曹明奎, 李克让 (2007). 中国森林生态 系统植被碳储量时空动态变化研究. 地理科学进展, 26(6), 1-10.]

Xu YL, Huang XY, Zhang Y, Lin WT, Lin ED (2005). Statistical analyses of climate change scenarios over China in the 21st Century. Advances in Climate Change Research, 1(2), 80-83. (in Chinese with English abstract) [许吟隆, 黄晓 荣, 张勇, 林万涛, 林而达 (2005). 中国21世纪气候变 化情景的统计分析. 气候变化研究进展, 1(2), 80-83.]

Xu YL, Jones RG (2004). Validating PRECIS with ECMWF Reanalysis Data over China. Agricultural Meteorology, 25(1), 5-9. (in Chinese with English abstract) [许吟隆, Jones RG (2004). 利用ECMWF再分析数据验证PRECIS对中国区域 气候的模拟能力. 中国农业气象, 25(1), 5-9.]

Xu YL, Zhang Y, Lin YH, Lin ED, Lin WT, Dong WJ, Jones RG, Hassell DC, Wilson S (2006). Analyses on the climate change responses over China under SRES B2 scenario using PRECIS. Chinese Science Bulletin, 51, 2068-2074. (in Chinese) [许吟隆, 张勇, 林一骅, 林而达, 林万涛, 董 文杰, Jones RG, Hassell DC, Wilson S (2006). 利用 PRECIS分析SRES B2情景下中国区域的气候变化响应. 科学通报, 51, 2068-2074. ]

Zhang SH, Peng GB, Huang M (2004). The feature extraction and data fusion of regional soil textures based on GIS techniques. Climatic and Environmental Research, 9(1), 65-79. (in Chinese with English abstract) [张时煌, 彭公 炳, 黄玫 (2004). 基于地理信息系统技术的土壤质地分 类特征提取与数据融合. 气候与环境研究, 9(1), 65-79.]

Zhao DS, Wu SH, Yin YH (2013). Responses of terrestrial ecosystems' net primary productivity to future regional climate change in China. PLoS ONE, 8(4), e60849. doi:10.1371/journal.pone.0060849.

Zhao M, Zhou GS (2004). Carbon storage of forest vegetation and its relationship with climatic factors. Scientia Geographica Sinica, 24, 50-54. (in Chinese with English abstract) [赵敏, 周广胜 (2004). 中国森林生态系统的 植物碳贮量及其影响因子分析. 地理科学, 24, 50-54.]

Zhou YR, Yu ZL, Zhao SD (2000). Carbon storage and budget of major Chinese forest types. Acta Phytoecologica Sinica, 24, 518-522. (in Chinese with English abstract) [周玉荣, 于振良, 赵士洞 (2000). 我国主要森林生态系统碳咜量 和碳平衡. 植物生态学报, 24, 518-522.]

责任编委: 韩士杰 责任编辑: 王 蒇 


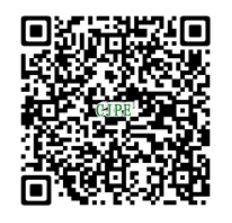

植物生态学报官网

唯一投稿网址

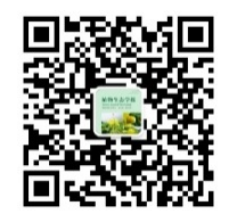

微信订阅号

期刊及学科

相关信息发布

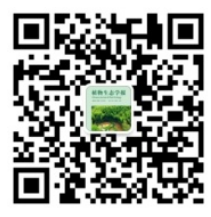

微信服务号

稿件状态查询

全文检索浏览 